
Not for reproduction, distribution or commercial use.

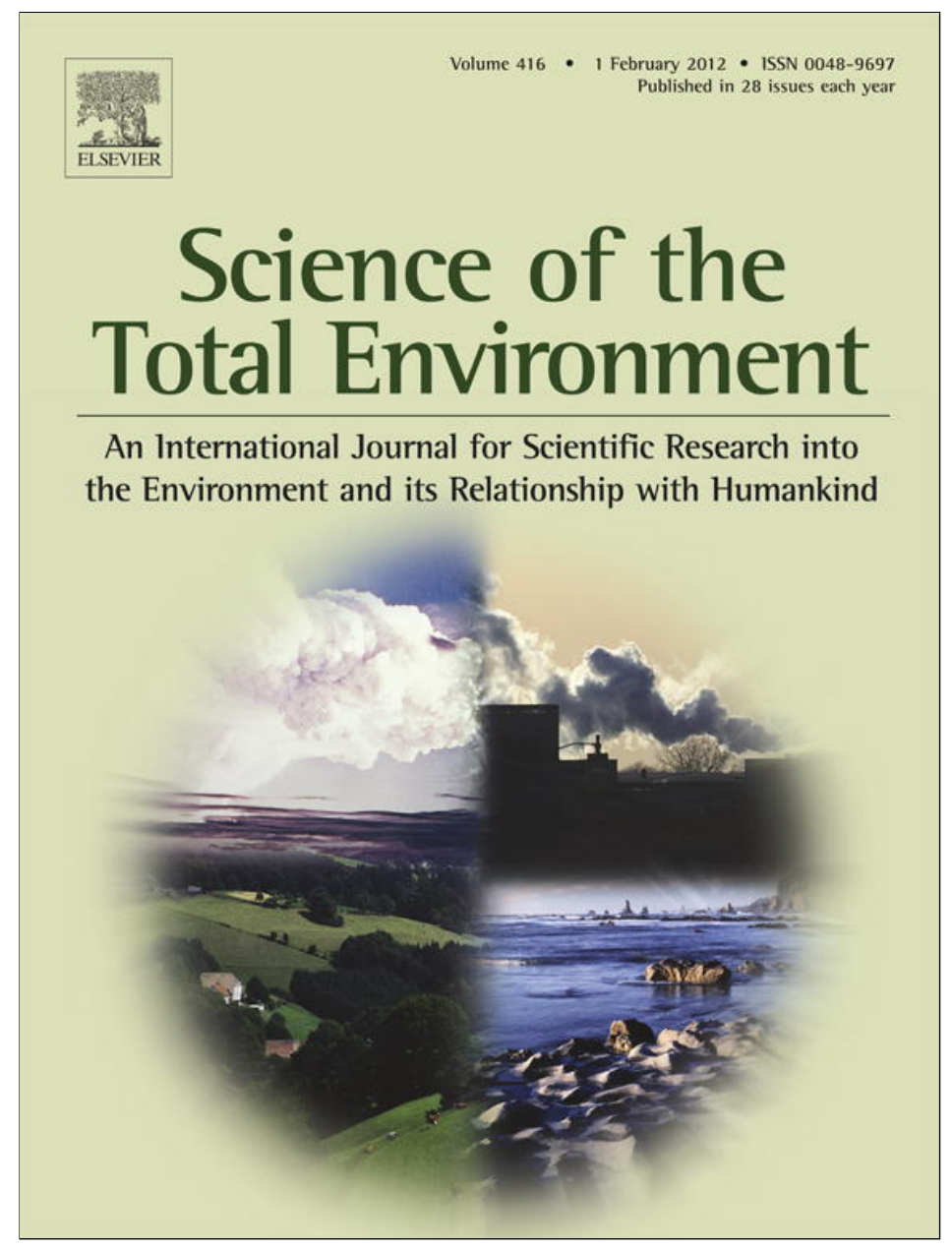

This article appeared in a journal published by Elsevier. The attached copy is furnished to the author for internal non-commercial research and education use, including for instruction at the authors institution and sharing with colleagues.

Other uses, including reproduction and distribution, or selling or licensing copies, or posting to personal, institutional or third party websites are prohibited.

In most cases authors are permitted to post their version of the article (e.g. in Word or Tex form) to their personal website or institutional repository. Authors requiring further information regarding Elsevier's archiving and manuscript policies are encouraged to visit:

http://www.elsevier.com/copyright 


\title{
Impacts of pesticides and natural stressors on leaf litter decomposition in agricultural streams
}

\author{
Jes Jesssen Rasmussen ${ }^{\text {a,* }}$, Peter Wiberg-Larsen ${ }^{\text {a }}$, Annette Baattrup-Pedersen ${ }^{\text {a }}$, \\ Rikke Juul Monberg ${ }^{\mathrm{b}}$, Brian Kronvang ${ }^{\mathrm{a}}$ \\ ${ }^{a}$ Department of Bioscience, Aarhus University, Vejlsøvej 25, 8600 Silkeborg, Denmark \\ ${ }^{\mathrm{b}}$ Department for Forest and Landscape, University of Copenhagen, Rolighedsvej 23, 1958 Frederiksberg C, Denmark
}

\section{A R T I C L E I N F O}

\section{Article history:}

Received 4 October 2011

Received in revised form 11 November 2011

Accepted 20 November 2011

Available online 15 December 2011

\section{Keywords:}

Macroinvertebrates

Microorganisms

Pesticide contamination

Leaf litter decomposition

Streams

Multiple stressors

\begin{abstract}
A B S T R A C T
Agricultural pesticides are known to significantly impact the composition of communities in stream ecosystems. Moreover, agricultural streams are often characterised by loss of physical habitat diversity which may impose additional stress resulting from suboptimal environmental conditions. We surveyed pesticide contamination and rates of leaf litter decomposition in 14 1st and 2nd order Danish streams using litter bags with coarse and fine mesh sizes. Two sites differing in physical habitat complexity were sampled in each stream, and we used this approach to differentiate the effects of pesticides between sites with uniform (silt and sand) and more heterogeneous physical properties.

Microbial litter decomposition was reduced by a factor two to four in agricultural streams compared to forested streams, and we found that the rate of microbial litter decomposition responded most strongly to pesticide toxicity for microorganisms and not to eutrophication. Moreover, the rate of microbial litter decomposition was generally $50 \%$ lower at sites with uniform physical habitats dominated by soft substrate compared to the sites with more heterogeneous physical habitats. The rate of macroinvertebrate shredding activity was governed by the density of shredders, and the density of shredders was not correlated to pesticide contamination mainly due to high abundances of the amphipod Gammarus pulex at all sites. Our study provides the first field based results on the importance of multiple stressors and their potential to increase the effect of agricultural pesticides on important ecosystem processes.
\end{abstract}

(c) 2011 Elsevier B.V. All rights reserved.

\section{Introduction}

Stream ecosystems are impacted by numerous anthropogenic stressors, and they remain some of the most impaired ecosystems on earth in terms of species extinction rates (MEA, 2005). However, one - yet unresolved question - is whether impacted ecosystems are able to maintain their ecological functions (Dudgeon et al., 2006). This emphasises the importance of addressing and characterising relationships between ecosystem function and anthropogenic stress.

Contamination of streams with pesticides applied in normal agricultural production is widely acknowledged as one of the greatest anthropogenic stressors to stream ecosystems (Meybeck, 2003; Schulz, 2004). Agricultural pesticides are primarily transported to stream recipients via runoff and flow through tile drains which highly coincide with heavy precipitation events (Kronvang et al., 2002; Neumann et al., 2002; Wauchope, 1978), and agricultural pesticides are proposed to pose a threat to all living organisms in stream ecosystems (Liess et al., 2005). Furthermore, streams draining agricultural land

* Corresponding autho rat: Department of Bioscience, Aarhus University, Vejlsøvej 25, 8600 Silkeborg, Denmark. Tel.: + 4587158895.

E-mail address: jr@dmu.dk (J.J. Rasmussen). are often characterised by loss of hydromorphological and habitat heterogeneity due to dredging and channelisation, increased concentrations of macronutrients, and increased transport of suspended material (Friberg et al., 2010; Pedersen, 2009). These effects may additionally have profound effects on ecosystem structure and function (Pedersen and Friberg, 2009; Piscart et al., 2009; Rasmussen et al., 2011a). In consequence, studies that investigate the combined effects of pesticides and other agriculturally related stressors are important in order to sufficiently protect organisms that reside in multistressor environments and to improve the environmental realism in the risk assessment of agricultural streams.

In streams, fungi and bacteria are key organisms in the decomposition and conversion of riparian plant litter into more palatable food resources for macroinvertebrate shredders and collectors/gatherers (Barlocher, 2005; Gessner et al., 2007). Aquatic fungi, mainly hyphomycetes, are dominant over bacteria during the earlier stages of leaf litter decomposition - even though the relative contribution of the two groups may change in severely impacted streams (Duarte et al., 2008a). Increased concentrations of nitrate and phosphate in streams due to loadings from agricultural diffuse sources have been shown to increase fungal biomass and rates of leaf decomposition (Gulis et al., 2006). However, several environmental parameters (e.g. water 
temperature) that are related to agricultural production probably act in concert to increase decomposition rates of leaf litter (Friberg et al., 2009a). Conversely, these effects might be counteracted by additional side-effects of the agricultural practices, i.e. the presence of pesticides and increased erosion and sediment transport (Young et al., 2008). Microbial organisms are not considered in the risk assessment procedure in spite of their important role in stream ecosystems. However, recent studies by Maltby et al. (2009) and Dijksterhuis et al. (2011) conclude that agricultural pesticides do pose a threat to aquatic fungi and that effect concentrations might be below the minimum allowed threshold concentrations for the standard test organisms. Moreover, Schäfer et al. (2011a) documented effects of pesticides on microbial leaf decomposition and fungal biomass in Australian streams and the authors highlighted the necessity for further research to sufficiently protect the microbial decomposing organisms. However, the potentially increased effect of pesticides in the presence of the stress that is related to loss of physical habitat heterogeneity and quality (e.g. increased siltation, increased amplitude of oxygen concentrations) on leaf decomposition has not been studied.

Macroinvertebrate shredders constitute the other major group of organisms that facilitate the conversion of leaf litter into secondary production and fine particulate organic matter, and the density of shredders in streams is tightly coupled to the temporal and spatial accumulation of coarse particulate organic matter (Graca, 2001). Furthermore, the food preference of shredders is strongly controlled by the nutritional quality of the food source, which is governed by the internal nutrient concentrations and the biomass of microbial organisms (Graca, 2001). Microcosm studies have indicated that shredding macroinvertebrates may reduce their consumption of litter after the exposing of shredder assemblages (Rasmussen et al., 2008) or leaves (Lauridsen et al., 2006) to pyrethroid insecticides. In addition, Schäfer et al. (2007) found that shredder induced leaf mass loss in agricultural streams in one of the studied biogeoregions was primarily explained by the fraction of species that are sensitive to periodic pesticide pollution (the SPEcies At Risk concept) reflecting that several shredders in the studied streams in addition were characterised as SPEAR (Liess and Von der Ohe, 2005). However, these findings are contrasted by those of other authors reporting that shredder densities and shredding activity did not respond to anthropogenic stress related to agriculture (Hagen et al., 2006). Shredder densities probably also respond strongly to physical habitat characteristics as many species of e.g. Plecoptera and Trichoptera are shredders with narrow habitat preferences for different types of substrate or vegetation (Dunbar et al., 2010). Thus reduced heterogeneity of physical habitats may have the potential to indirectly reduce rates of litter decomposition beyond the effect of pesticides alone.

We conducted field investigations in 14 streams that represented a gradient in agricultural activity. Two sites with differing physical complexity were sampled in each stream to differentiate the effects of pesticides on microbial decomposition and macroinvertebrate shredding activity between sites with high or low physical habitat heterogeneity. More specifically we tested the hypotheses that 1) the rate of microbial litter decomposition decreases with increasing pesticide toxicity to microbial leaf decomposers, 2) the rate of microbial leaf decomposition is lower at sites that are characterised by uniform physical conditions (due to side-effects of agriculture as siltation and previous dredging activity) compared to sites with more diverse physical conditions 3 ) shredding activity decreases with increasing pesticide toxicity to macroinvertebrates (direct effects) and to microorganisms (indirect effects through decreasing nutritional value of leaves - using microbial activity as a proxy for microbial biomass and nutritional value), and 4) macroinvertebrate shredding activity is further reduced at sites with homogeneous physical conditions due to lower density of macroinvertebrate shredders.

\section{Materials and methods}

\subsection{Study area}

The field campaign was conducted in the months April to August, 2009 in two catchments on the island of Funen (Denmark) that are characterised by low elevation and loamy soils with medium to low infiltration capacity. The climatic conditions are temperate and yearly precipitation averages $700 \mathrm{~mm}$. Agriculture is the dominant land use (67\%) with small forest patches and urban areas embedded in the landscape. The dominant defoliating tree is beech (Fagus sylvatica). For further details on the study area, consult Rasmussen et al. (2011b). In total, fourteen streams of 1st and 2nd order were surveyed and catchment areas ranged from 18 to 73 ha (Fig. 1).

The stream selection was based on a series of criteria: 1) yearround water flow, 2) no dredging and weed cutting during the sampling period, and 3) no sources of pollution other than from agriculture. The streams represent a gradient of potential pesticide contamination predicted from the proportion of adjacent agricultural land (Rasmussen et al., 2011b).

Two stream reaches $(50 \mathrm{~m})$ were selected in each of the study streams based on the physical properties of the reach (Fig. 2). The criteria for selecting the stream reaches were: i) presence of an upstream reach characterised by low current velocity, low physical diversity, low reaeration capacity; ii) a downstream reach characterised by fast flow, high physical diversity, and high reaeration capacity; iii) that the distance between paired reaches should not exceed $250 \mathrm{~m}$. The consequent upstream positioning of the reaches that were characterised by low physical diversity was supposed to minimise the potential bias from accidental downstream drift of macroinvertebrates that are strongly associated with habitat types that are not present at the reaches with low physical diversity. For convenience, reaches are referred to as sampling sites in the following parts of the paper.

\subsection{Physicochemical variables}

Three litre water samples were collected at the downstream site of each stream $(n=14)$ in each of the months April, June and August for general description of the water chemistry (Table 1 ). Stream specific water chemistry is presented in Appendix A. The following parameters were analysed according to European standards: BOD $_{5}$ (DS/EN 1899 1999), ortho-phosphate (DS/EN 1189-1997) and ammonia-N (DS 11732 2005). Nitrate-N was analysed using Lachat-methods (Lachat Instruments, USA, Quickchem. no. 10-107-06-33-A (Salycate method)). Chloride concentration was measured using silver nitrate $\left(\mathrm{AgNO}_{3}\right)$ (APHA, 1998). Concentrations of total $\mathrm{N}$ and total $\mathrm{P}$ were measured (unfiltered samples) applying the Kjeldahl-N method (Kjeldahl, 1883) and Danish standard (DS-291), respectively.

At each sampling site, twenty-five transects were established with two meter intervals. In each transect, wetted width (W), depth (D) and water velocity (at $0.6 \times$ depth - from the surface) (U) were measured at four points corresponding to 25, 50, 75 and $100 \%$ of the wetted width using a flow-meter (Höntzsch $\mu$ P-TAD). Four rectangular plots were established between each pair of transects ( $2 \mathrm{~m} \times 25 \%$ of wetted width). In each plot, substrate type and total macrophyte coverage were estimated. Submergent and emergent macrophytes were identified to the lowest possible taxonomical level. Furthermore, proportional coverage was estimated for each taxon. Stream water temperature, conductivity and oxygen concentration were registered using a multi-meter (WTW multi350i) and $\mathrm{pH}$ was measured applying a (YSI-60) pH-meter (Table 1). Sampling site specific physical characteristics are presented in Appendix B. 

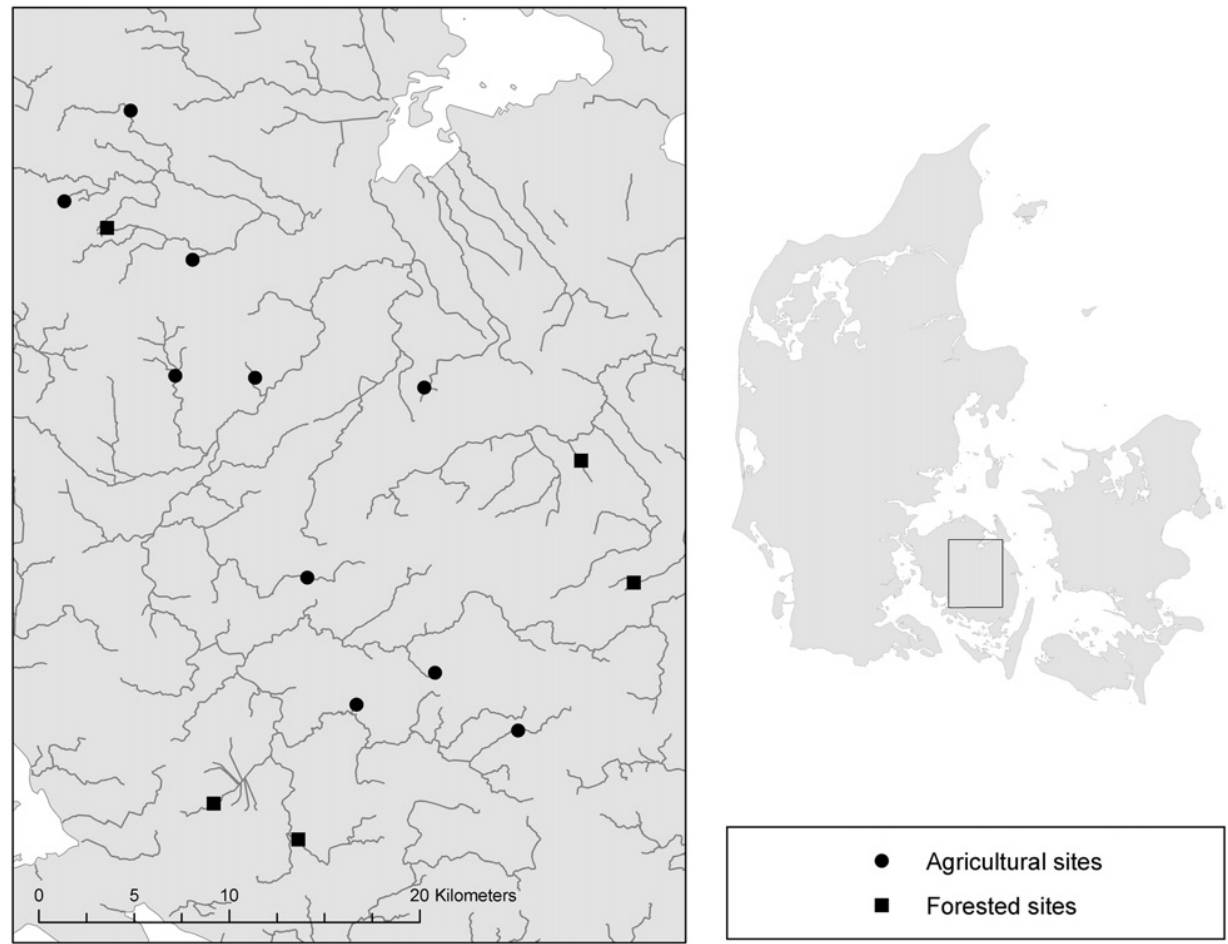

Fig. 1. Geographical distribution of the study streams.

\subsection{Quantification of pesticide contamination}

In total, 19 herbicides, 6 fungicides and 6 insecticides were included in the sampling program. The selected list of pesticides represented the most frequently applied compounds in Danish agriculture in 2008 supplemented by a series of banned pesticides that are commonly found in groundwater. The methods used for

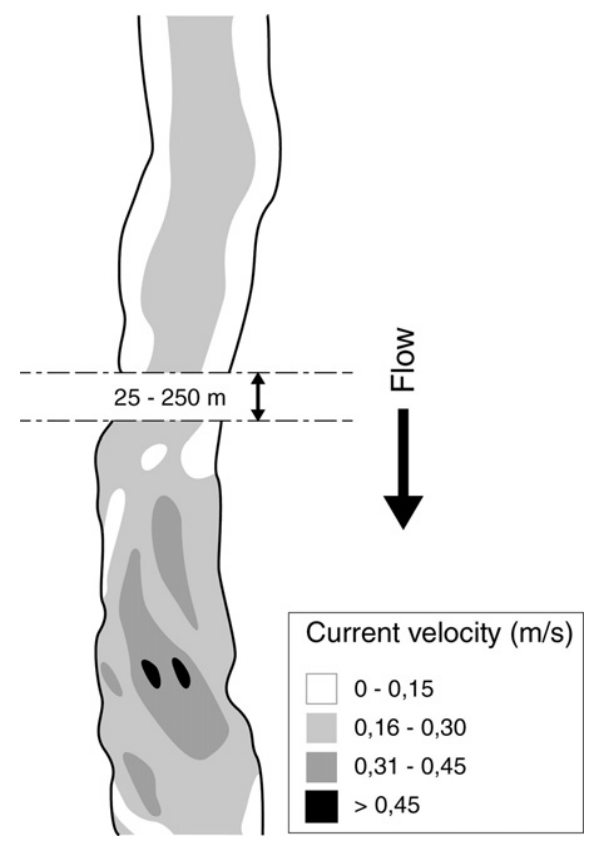

Fig. 2. Schematic presentation of the paired sites representing uniform (upstream) and diverse (downstream) physical habitats. Each sampling site represents a $50 \mathrm{~m}$ reach. Current velocity is used as a surrogate measure for the spatial distribution of physical habitat types as current velocity has a direct effect on substrate types, turbulence and reaeration. pesticide sampling and quantification have been published elsewhere (Rasmussen et al., 2011b).

Pesticide contamination during heavy precipitation events (representing runoff and flow through tile-drains) was characterised using event triggered water samplers during the months May and June

Table 1

Average, standard deviation, minimum and maximum values for physical and chemical parameters measured in 14 Danish streams. Dashes indicate that values were below detection limit.

\begin{tabular}{|c|c|c|c|c|}
\hline Parameter & Average & $\begin{array}{l}\text { Standard } \\
\text { deviation }\end{array}$ & Minimum & Maximum \\
\hline Agriculture in catchment $(\%)^{\mathrm{b}}$ & 51.7 & 38.8 & 2.2 & 100 \\
\hline Minimum buffer strip width $(\mathrm{m})^{\mathrm{b}}$ & 7.9 & 7.8 & 1 & 25 \\
\hline \multicolumn{5}{|l|}{ Physical } \\
\hline Discharge $\left(\mathrm{L} \mathrm{s}^{-1}\right)^{\mathrm{a}}$ & 3.8 & 3.7 & - & 13.1 \\
\hline Current velocity $\left(\mathrm{m} \mathrm{s}^{-1}\right)^{\mathrm{a}}$ & 0.04 & 0.06 & - & 0.16 \\
\hline Shear stress ${ }^{\mathrm{a}}$ & 5.9 & 2.9 & - & 11 \\
\hline Width $(\mathrm{m})^{\mathrm{a}}$ & 1.3 & 0.5 & 0.55 & 2.5 \\
\hline Depth $(\mathrm{m})^{\mathrm{a}}$ & 0.06 & 0.05 & 0.02 & 0.29 \\
\hline Boulder $(\%)^{a}$ & 9.1 & 9.2 & 0 & 33.5 \\
\hline Gravel (\%) ${ }^{\mathrm{a}}$ & 26.8 & 21.5 & 0 & 66.7 \\
\hline Sand $(\%)^{\mathrm{a}}$ & 21.3 & 14.6 & 0 & 58.0 \\
\hline Silt $(\%)^{\mathrm{a}}$ & 33.2 & 24.7 & 3.3 & 89.3 \\
\hline Debris (\%) ${ }^{\mathrm{a}}$ & 7.3 & 7.7 & 0.6 & 35.3 \\
\hline \# Macrophyte species ${ }^{a}$ & 2.6 & 1.5 & 0 & 6 \\
\hline Total macrophyte coverage (\%) & 17.8 & 15.2 & 0 & 67 \\
\hline Temperature $\left({ }^{\circ} \mathrm{C}\right)^{\mathrm{a}}$ & 13.3 & 1.7 & 10.9 & 16.7 \\
\hline \multicolumn{5}{|l|}{ Chemical } \\
\hline $\mathrm{BOD}_{5}\left(\mathrm{mg} \mathrm{L}^{-1}\right)^{\mathrm{a}}$ & 1.91 & 0.62 & 0.96 & 3.05 \\
\hline Oxygen concentration $\left(\mathrm{mg} \mathrm{L}^{-1}\right)^{\mathrm{a}}$ & 8.25 & 1.04 & 5.94 & 10.21 \\
\hline Ammonia $\left(\mathrm{mg} \mathrm{L}^{-1}\right)^{\mathrm{a}}$ & 0.07 & 0.06 & 0.01 & 0.19 \\
\hline Nitrate $\left(\mathrm{mg} \mathrm{L}^{-1}\right)^{\mathrm{a}}$ & 2.27 & 1.57 & 0.59 & 6.66 \\
\hline Total N $\left(\mathrm{mg} \mathrm{L}^{-1}\right)^{\mathrm{a}}$ & 2.9 & 1.61 & 1.19 & 7.48 \\
\hline Ortho-phosphate $\left(\mathrm{mg} \mathrm{L}^{-1}\right)^{\mathrm{a}}$ & 0.07 & 0.04 & 0.02 & 0.14 \\
\hline Total $\mathrm{P}\left(\mathrm{mg} \mathrm{L}^{-1}\right)^{\mathrm{a}}$ & 0.13 & 0.05 & 0.06 & 0.24 \\
\hline Chloride $\left(\mathrm{mg} \mathrm{L}^{-1}\right)^{\mathrm{a}}$ & 30.73 & 4.53 & 22.58 & 38.68 \\
\hline Sulphate $\left(\mathrm{mg} \mathrm{L}^{-1}\right)^{\mathrm{a}}$ & 49.77 & 19.93 & 28.63 & 75.25 \\
\hline Suspended matter $\left(\mathrm{mg} \mathrm{L}^{-1}\right)^{\mathrm{a}}$ & 9.63 & 4.40 & 3.80 & 19.57 \\
\hline
\end{tabular}

arameter measured on a reach level $(n=28)$.

b Parameter measured on a stream level $(n=14)$. 
(Liess and Von der Ohe, 2005). Event triggered samplers were deployed just downstream of the downstream sampling site. Thus, sample represents both sampling sites as it was assumed that the pesticide contamination was not significantly different between sites. The sampling system consisted of two $1 \mathrm{~L}$ glass bottles that were deployed in the flowing part of the stream channel. Bottles were filled passively through small $(0.5 \mathrm{~cm}$ in diameter) glass tubes when the water level increased above the glass tube opening. The two bottles were positioned $5 \mathrm{~cm}$ and $10 \mathrm{~cm}$ above base flow water level, respectively. During the sampling period, two precipitation episodes triggered the sampling system of which the last was the only episode triggering the samplers in all streams. In addition, we collected water samples (1 L) in August during low flow conditions to characterise pesticide input that originated from groundwater inflow. However, these results are disregarded in this paper since the groundwater input of pesticides was characterised by only few herbicide compounds in low concentrations. See also Rasmussen et al. (2011b) for further details.

Retrieved samples were all sent to the OMEGAM laboratories in Amsterdam for pesticide analyses (including sample filtering and solid phase extraction). The final extract of each sample was processed using gas-chromatography mass-spectrometry (GC-MS) or liquid-chromatography mass-spectrometry (LC-MS). Results were corrected for recovery, which was determined by Omegam laboratories. For further details consult Rasmussen et al. (2011b).

\subsection{Macroinvertebrates}

Macroinvertebrates were sampled in April, June and August, 2009 using randomised surber sampling (each sample covering $200 \mathrm{~cm}^{2}$ ). Five surber samples were collected from each sampling site $(n=28)$ in each sampling month and samples were preserved in $70 \%$ ethanol in the field. All macroinvertebrates were counted and identified to genus or species level, except Chironomidae (sub-family), Simuliidae (family) and Oligochaeta (order) (Appendix C). Feeding functional groups were assigned to each taxon according to Tachet et al. (2002), and the density of shredders was calculated. In addition, the abundance of SPEcies At Risk for being impacted by periodic pesticide contamination (\%SPEAR abundance) was computed for each site and sampling using the freely available online SPEAR calculator (http:// www.systemecology.eu/SPEAR/index.php) (Appendix C).

\subsection{Leaf decomposition}

Newly fallen beech leaves ( $F$. sylvatica) were used for studying leaf decomposition. The leaves were retrieved from the forest floor in Velling forest, Denmark in the autumn of 2008. The forest catchment is entirely characterised by old beech forest, and collected leaves were not supposed to be exposed to significant environmental pollutants prior to the study. The collected leaves were air-dried in a climate chamber at $15^{\circ} \mathrm{C}$ and subsequently stored at $4{ }^{\circ} \mathrm{C}$.

On May 1 st we mounted 15 leaf bags with fine mesh size $(500 \mu \mathrm{m})$ and 15 leaf bags with coarse mesh size $(9 \mathrm{~mm})$ to the stream bed at each sampling site. Riffle sections were preferred when possible to minimise siltation and because litter material primarily accumulates at these sites. However, none of the sites that were characterised by uniform physical conditions contained distinct riffle sections, and the leaf bags were deployed on the hardest substrate that was available at the sampling site. Leaf bags with fine mesh size contained $0.38 \pm 0.02 \mathrm{~g}$ DW, and leaf bags with coarse mesh size contained $0.75 \pm 0.02 \mathrm{~g}$ DW. Only unbroken leaves were used. However, the petiole was removed from all leaves to increase the signal of biological decomposition processes. Three leaf bags with fine and coarse mesh size, respectively, were sampled after 14, 21, 35, 49 and 80 days. Sediment material and macroinvertebrates were removed in the laboratory by gently rinsing the leaf packs in demineralised water in white trays and subsequently the leaves were dried at
$60{ }^{\circ} \mathrm{C}$ to constant mass (48-72 h). The dry weight of the remaining leaf material in each leaf bag was measured (three decimals accuracy) using a Mettler Toledo XP-204. Leaf pack weight loss reflects microbial activity and leaching (fine mesh bags) whereas the weight loss in coarse mesh bags additionally reflects shredding activity and abrasion.

\subsection{Data analysis}

The remaining dry mass of beech leaves was fit to the exponential decay model $\mathrm{m}_{\mathrm{t}}=\mathrm{m}_{0} * \mathrm{e}^{-k \mathrm{t}}$ where $\mathrm{m}_{\mathrm{t}}$ is the leaf dry mass remaining at time $t, m_{0}$ is the initial dry mass, and $k\left(\right.$ day $\left.^{-1}\right)$ is the rate of leaf decomposition. The physical leaching of soluble compounds may account for 4 to $42 \%$ of the total leaf biomass, and this mass loss will be effectuated within 2 to 7 days after leaf submergence (Abelho, 2001). In consequence, we used the leaf bags that were retrieved after 14 days as initial dry mass to minimise the noise from physical compound leaching. Shredder decomposition rates ( $k_{\text {shredders }}$ day $^{-1}$ ) (coarse meshed bags) were corrected for microbial decomposition $\left(k_{\text {microbial }}\right.$ day $\left.^{-1}\right)$.

The toxicity of the measured pesticide concentrations for macroinvertebrates and microbial organisms was quantified using Toxic Units (TU)

$\log \mathrm{TU}=\log \left(\mathrm{C}_{i} / \mathrm{EC} 50_{i}\right)$

where $C_{i}$ is the concentration of the compound $i$ and $\mathrm{EC} 50_{i}$ is the median acute effect concentration of a standard test species. Daphnia magna was selected as standard test species for macroinvertebrates. Since there is no standard test species available for microorganisms, we used species of aquatic hyphomycetes when available and Selenastrum capricornutum for the remaining compounds as surrogate microorganisms to estimate the potential toxic effect on microbial leaf decomposers (log $\mathrm{TU}_{\text {microbial }}$ ) (Schäfer et al., in press). The summed and the $\log$ maximum TU were calculated for all samples for both $D$. magna and microorganisms. We only report log maximum TUs (log mTU) as the $\log$ sum TUs and $\log$ mTUs were highly intercorrelated for D. magna and microorganisms ( $r>0.85, \mathrm{P}<0.001)$. Furthermore, applying the log sum TUs did not significantly improve relationships with biotic endpoints compared to the log mTUs which are consistent with previous findings (Schäfer et al., 2007; Schäfer et al., in press).

In order to identify if the experimental set-up was successful in separating the two agriculturally related stressors of pesticide contamination and loss of physical habitat heterogeneity, a Principal Component Analysis (PCA) of all physical and chemical variables was performed using PC-ORD 4.25. Four groups were identified in the PCA, and the groups were identified as significantly different using the site scores in a one-way analysis of variance.

We tested for differences between average $k_{\text {microbial }}$ and $k_{\text {shredders }}$ for each of the four groups of sampling sites that were identified with the PCA using a two-way analysis of variance. We used Pearson's correlation analyses to evaluate the effect of all measured environmental parameters and shredder metrics on site specific $k_{\text {microbial }}$ and $k_{\text {shredders }}$ in SAS Enterprise Guide 4.2. Analysis of covariance was used to identify potential differences in slopes and intercepts of the regression lines that characterised log mTU (for microorganisms and D. magna) as a function of $k$ (for microorganisms and shredders, respectively). In addition to the $k_{\text {shredders }}$ we applied $k_{\text {shredders }}$ that was normalised according to the population density of shredders to evaluate if there was an effect at the level of individuals. Analyses of covariance were conducted in Sigma-Plot 11.0.

The potential indirect effect of agricultural pesticides on shredding activity (through a reduction in nutritional value of the litter) was tested using a Spearman Rank correlation analysis on the relation between $k_{\text {microbial }}$ and $k_{\text {shredders. }}$ Moreover, we tested if the relative proportion of agriculture in the catchment had an effect on the ratio 
$\left(k_{\text {microbial }} / k_{\text {shredders }}\right)$ using Spearman Rank correlation. All correlation analyses were performed in SAS Enterprise Guide 4.2.

\section{Results}

\subsection{Pesticides and $T U$}

In total 13 herbicides, 5 fungicides and 2 insecticides were detected in the stream water samples (Table 2). Sum concentrations ranged from 0.01 to $3.17 \mu \mathrm{g} \mathrm{L}^{-1}$, and the number of detected pesticides per water sample ranged from 1 to 13 . The log $\mathrm{mTU}_{D \text {.magna }}$ ranged from -6.63 to -1.72 , and $\log \mathrm{mTU}_{\text {microbial }}$ ranged from -4.03 to -0.63 . The carbamate insecticide pirimicarb was clearly the most important contributor to high values of $\log \mathrm{mTU}_{D . \text { magna }}$ followed by the strubilurine fungicide azoxystrobin. The fungicides dimethomorph (morpholine) and propiconazole (triazole) and the dinitroaniline herbicide pendimethalin were the most important compounds governing high values of log $\mathrm{mTU}_{\text {microbial. }}$

\subsection{Physico-chemical parameters}

Several environmental parameters were significantly intercorrelated $(P \mid>0.05)$, and in these cases we selected the environmental parameter that was most strongly correlated to $k_{\text {microbial }}$ and $k_{\text {shredders. }}$ We used $\log \mathrm{mTU}_{\text {microbial }}$ as measure for pesticide contamination, because this parameter was clearly more strongly correlated with environmental parameters than $\mathrm{mTU}_{\text {D.magna }}$ and we pooled the different types of hard substrate (gravel and boulder) in one category to increase overall trends. The Principal Component Analysis (PCA) of physical and chemical variables was conducted using a strep-wise forward selection excluding insignificant environmental parameters. The final PCA was conducted using the proportion of silt, chloride concentration, $\log \mathrm{mTU}_{\text {microbial }}$, discharge, the proportion of debris, discharge and $\mathrm{BOD}_{5}$ as environmental parameters. Axis 1, explaining $50.5 \%$ of the variation in the data set, separated the sites with forested catchments ( $>50 \%$ forest) from those with agricultural catchments

\section{Table 2}

Detected pesticide compounds in stream water of 14 Danish streams. Three samples were collected from each stream of which two were samples with event-triggered samplers during May and June and one was sampled manually during base-flow in August.

\begin{tabular}{llccc}
\hline Compound & $\begin{array}{l}\text { Max } \\
\text { concentration } \\
\text { (ug/L) }\end{array}$ & $\begin{array}{l}\text { Detection } \\
\text { frequency } \\
(\%)\end{array}$ & $\begin{array}{c}\text { Maximum } \\
\mathrm{TU}_{\text {D.magna }}{ }^{\mathrm{a}}\end{array}$ & $\begin{array}{l}\text { Maximum } \\
\mathrm{TU}_{\text {microbial }}\end{array}$ \\
\hline Aclinofen (H) & 0.14 & 7 & -3.93 & $-1.54^{\mathrm{c}}$ \\
Atrazine (H) & 0.02 & 7 & -6.63 & $-3.81^{\mathrm{c}}$ \\
Desethylterbutylazine (H) & 0.11 & 100 & -4.65 & $-2.99^{\mathrm{c}}$ \\
Diflufenican (H) & 0.15 & 29 & -3.20 & $-2.08^{\mathrm{c}}$ \\
Hexazinone (H) & 0.06 & 7 & -6.15 & $-2.4^{\mathrm{c}}$ \\
Metachlor (H) & 0.05 & 57 & -5.82 & $-2.2^{\mathrm{c}}$ \\
Metamitron (H) & 0.12 & 7 & -4.68 & $-2.52^{\mathrm{c}}$ \\
Pendimethaline (H) & 0.97 & 14 & -2.46 & $-0.92^{\mathrm{c}}$ \\
Propyzamide (H) & 0.43 & 21 & -4.11 & $-3.23^{\mathrm{c}}$ \\
Prosulfocarb (H) & 0.07 & 21 & -3.86 & $-3.21^{\mathrm{c}}$ \\
Simazine (H) & 0.03 & 7 & -4.56 & $-3.12^{\mathrm{c}}$ \\
Terbutylazine (H) & 0.6 & 57 & -4.55 & $-2.26^{\mathrm{c}}$ \\
Azoxystrobin (F) & 0.51 & 43 & -2.77 & $-1.92^{\mathrm{b}}$ \\
Boscalid (F) & 0.72 & 36 & -3.87 & $-2.82^{\mathrm{c}}$ \\
2,4 Dichlorophenoxyacetic & 0.05 & 7 & -6.18 & $-3.71^{\mathrm{c}}$ \\
$\quad$ acid (H) & & & & \\
Dimethomorph (F) & 0.08 & 14 & -5.12 & $-0.63^{\mathrm{b}}$ \\
Propiconazole (F) & 0.27 & 43 & -4.58 & $-0.88^{\mathrm{c}}$ \\
Tebuconazole (F) & 0.24 & 50 & -4.24 & $-2.99^{\mathrm{b}}$ \\
Dimethoate (I) & 0.18 & 14 & -4.05 & $-6.11^{\mathrm{c}}$ \\
Pirimicarb (I) & 0.32 & 21 & -1.72 & $-5.64^{\mathrm{c}}$ \\
\hline Based on the LC50 & & & & \\
\hline
\end{tabular}

a Based on the LC50 derived from $48 \mathrm{~h}$ acute toxicity tests.

b Based on species of aquatic hyphomycetes.

c Based on Selenastrum capricornosum.
( $>50 \%$ agriculture). Axis 2 , additionally explaining $28.5 \%$ of the variation in the data set, separated the upstream sites with uniform physical conditions from the downstream sites with more diverse physical conditions. Positive values on axis 2 are characterised by higher proportions of boulder and gravel whereas negative values are characterised by higher proportions of silt. The PCA separated the sampling sites into four significantly different groups according to land-use characteristics and physical habitat properties $(\mathrm{P}<0.05)$ (Fig. 3).

\subsection{Leaf decomposition}

Regression coefficients for the fitted exponential decay functions averaged $0.71 \pm 0.22$ and $0.54 \pm 0.21$ for leaf bags with fine and coarse mesh sizes, respectively (data not shown). Relative weight loss ranged from 46 to $100 \%$ in leaf bags with coarse mesh size and from 0 to $52 \%$ in leaf bags with fine mesh size.

The average rate of microbial leaf decomposition ( $\left.k_{\text {microbial }}\right)$ was significantly different amongst the site groups that were identified using PCA on environmental variables (Fig. 4$)(\mathrm{P}<0.05)$. The average $k_{\text {microbial }}$ for forested sites was significantly higher than the average $k_{\text {microbial }}$ for agricultural sites $(\mathrm{P}<0.001)$ and the average $k_{\text {microbial }}$ for forested sites with diverse physical conditions $\left(k_{\text {microbial }}=0.0084\right.$ day $\left.^{-1}, \mathrm{n}=5\right)$ was significantly higher than the average $k_{\text {microbial }}$ for forested sites with uniform physical conditions $\left(k_{\text {microbial }}=0.0047\right.$ day $\left.^{-1}, \quad \mathrm{n}=5\right)$ $(\mathrm{P}<0.05)$. However, the average $k_{\text {microbial }}$ for agricultural sites with diverse physical conditions $\left(k_{\text {microbial }}=0.0026 \mathrm{day}^{-1}, \mathrm{n}=9\right.$ ) was not significantly different from the average $k_{\text {microbial }}$ for agricultural sites with uniform physical conditions $\left(k_{\text {microbial }}=0.0016\right.$ day $^{-1}, \quad \mathrm{n}=9$, $\mathrm{P}=0.061)$. The average rate of shredder decomposition ( $\left.k_{\text {shredders }}\right)$ for the respective stream sites was not significantly different amongst the site groups that were identified using PCA on environmental variables $(\mathrm{P}>0.05$, Appendix $\mathrm{D})$. Normalising the average rate of shredder decomposition to the level of individuals did not provide significantly different results (data not shown).

We found that the most important environmental parameter governing the $k_{\text {microbial }}$ was $\log \mathrm{mTU}_{\text {microbial }}(\mathrm{r}=-0.72, \mathrm{P}<0.001)$ followed by the $\log \mathrm{mTU}_{\text {D.magna }}(\mathrm{r}=-0.63, \mathrm{P}<0.001)$, the relative proportion of agriculture in the catchment $(\mathrm{r}=-0.58, \mathrm{P}<0.001)$ and the logarithm to the total concentrations of pesticides $(r=0.56$, $\mathrm{P}=0.025$ ) (Appendix E). On average, the concentrations of ammonia$\mathrm{N}$ and nitrate- $\mathrm{N}$ were two times higher in agricultural streams whereas there were no significant differences in concentrations of orthophosphate. However, no macro- or micronutrient concentrations were significantly correlated with rates of microbial or shredder decomposition. Subdividing the sites according to their physical properties further increased the correlation coefficient for the regression between $k_{\text {microbial }}$

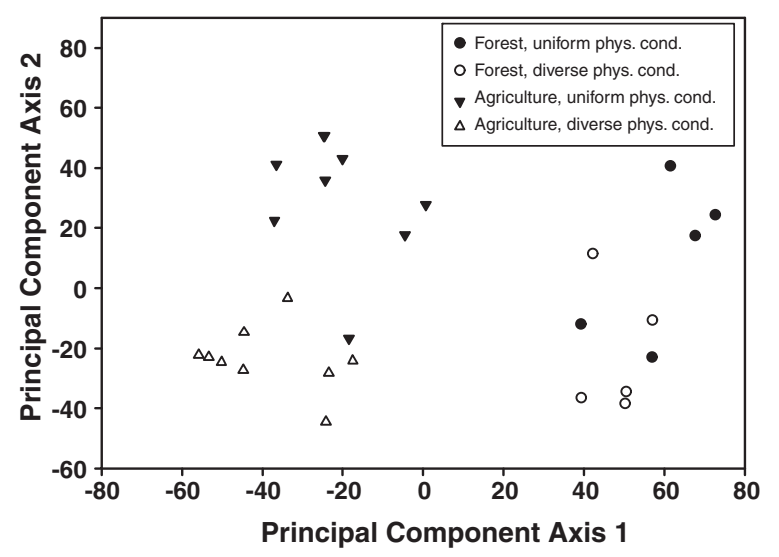

Fig. 3. Principal Component Analysis (PCA) of physico-chemical parameters for 28 reaches $(50 \mathrm{~m})$. Loading of PCA axis $1=50.5 \%$ and loading of PCA axis $2=28.5 \%$. 


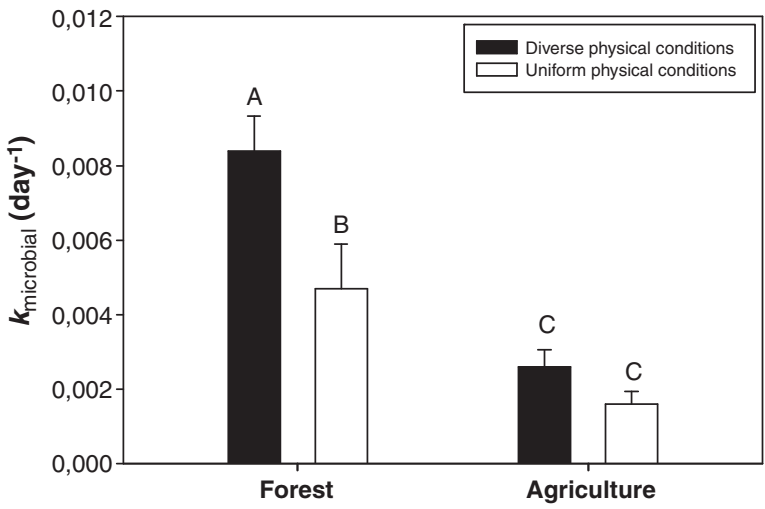

Fig. 4. Rates of microbial leaf decomposition ( $\left.k_{\text {microbial }}\right)$ in 14 streams. Data represents two sampling sites in each of the streams and were characterised by diverse or uniform physical conditions, respectively. Grouping of sampling sites was based on a PCA on environmental variables (see Fig. 3). Error bars indicate SE of the mean, and capital letters indicate significantly different groups $(\mathrm{P}<0.05)$.

and $\log \mathrm{mTU}_{\text {microbial }}(\mathrm{r}=-0.76, \mathrm{P}<0.001$ and $\mathrm{r}=-0.71, \mathrm{P}<0.005$, for sites with diverse and uniform physical conditions, respectively) (Fig. 5). There was no significant difference between the slopes of the regression lines $(\mathrm{P}>0.05)$ representing $k_{\text {microbial }}$ as a function of $\log$ $\mathrm{mTU}_{\text {microbial, }}$, but the intercepts were significantly different $(\mathrm{P}<0.05)$ (Fig. 5).

The rate of leaf decomposition in the leaf bags with shredders ( $k_{\text {shredders }}$ ) was significantly correlated to the site-based individual density of shredders and the proportional coverage of silt (Table 3 ). However, shredder densities for April, June and August were not correlated with the proportional coverage of silt $(\mathrm{r}=0.15, \mathrm{P}>0.05, \mathrm{n}=28)$. The $\log \mathrm{mTU}_{\text {D.magna }}$ was not significantly correlated with $k_{\text {shredders }}$ $(\mathrm{P}>0.05$, Appendix E, F). Normalising rates of shredder decomposition to the level of individuals did not provide significant correlations to pesticide parameters. Similarly, subdividing the sites according to their physical properties and/or land-use characteristics did not provide significant correlations with pesticide parameters (data not shown). The freshwater amphipod Gammarus pulex was clearly the dominating species of shredding macroinvertebrates in terms of individual density on average accounting for more than $75 \%$ of the total shredder density (Appendix C).

The ratio between $k_{\text {microbial }}$ and $k_{\text {shredders }}$ decreased with increased agricultural activity in the catchment $(\mathrm{r}=0.72, \mathrm{P}<0.001)$ (Fig. 6). The ratio between $k_{\text {microbial }}$ and $k_{\text {shredders }}$ additionally decreased

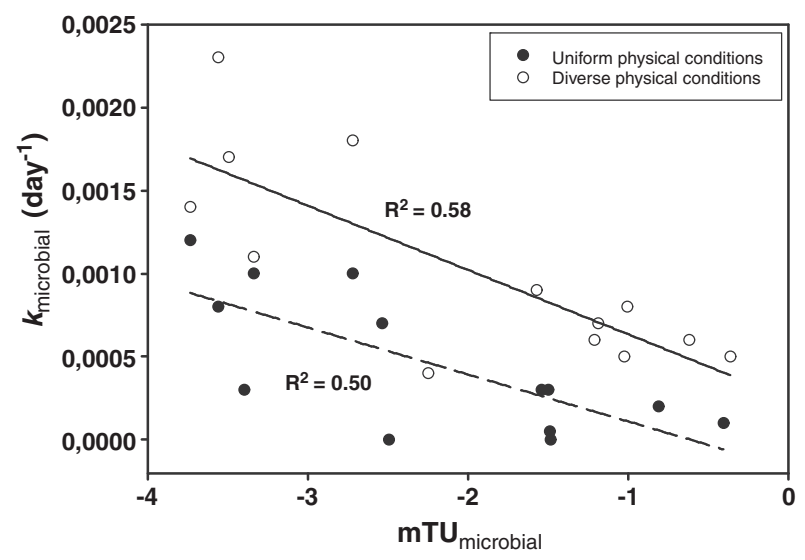

Fig. 5. The rate of microbial leaf decomposition $\left(k_{\text {microbial }}\right)$ as a function of the log mTUmicrobial measured in 14 Danish streams with event triggered samplers. Data represents two neighbouring sites from each stream with the upstream site being characterised by uniform physical habitats and the downstream site being characterised by diverse physical habitats.
Table 3

Shredder densities for 14 paired stream sites that differ with respect to diversity of the physical habitats $( \pm \mathrm{SE})$. Shredder densities are based on 5 surber samples collected from each site in the months April, June and August, 2009. Furthermore, the Pearson $r$ is presented for the correlations between the rate of leaf decomposition ascribed to shredders $\left(k_{\text {shredders }}\right)$ and shredder densities for all sites in each of the sampling months. Asterisks indicate the level of significance.

\begin{tabular}{|c|c|c|c|c|}
\hline & All sites & $\begin{array}{l}\text { Sites with } \\
\text { uniform } \\
\text { physical } \\
\text { conditions }\end{array}$ & $\begin{array}{l}\text { Sites with } \\
\text { diverse } \\
\text { physical } \\
\text { conditions }\end{array}$ & $\begin{array}{l}\text { Pearson } r \text { for } \\
k_{\text {shredders }} \\
\text { (all sites) }\end{array}$ \\
\hline $\begin{array}{l}\text { Shredder density (April) } \\
\text { (ind. } \mathrm{m}^{-2} \text { ) }\end{array}$ & $2794 \pm 402$ & $2918 \pm 571$ & $2669 \pm 598$ & $0.47^{*}$ \\
\hline $\begin{array}{l}\text { Shredder density (June) } \\
\quad \text { (ind. } \mathrm{m}^{-2} \text { ) }\end{array}$ & $5693 \pm 1429$ & $7071 \pm 2696$ & $4313 \pm 960$ & $0.52^{* *}$ \\
\hline $\begin{array}{l}\text { Shredder density } \\
\quad \text { (August) (ind. } \mathrm{m}^{-2} \text { ) }\end{array}$ & $4515 \pm 694$ & $4413 \pm 1150$ & $4616 \pm 827$ & $0.52^{* *}$ \\
\hline $\begin{array}{l}\text { Average shredder } \\
\text { density (ind. } \mathrm{m}^{-2} \text { ) }\end{array}$ & $4226 \pm 716$ & $4696 \pm 1335$ & $3756 \pm 559$ & $0.61^{* *}$ \\
\hline
\end{tabular}

significantly with increasing $\log \mathrm{mTU}_{\text {D.magna }}(\mathrm{r}=0.61, \mathrm{P}<0.01)$ and $\log \mathrm{mTU}_{\text {microbial }}(\mathrm{r}=0.45, \mathrm{P}<0.05)$ (data not shown).

\section{Discussion}

\subsection{Impacts of pesticides on microbial leaf decomposition}

The rate of microbial decomposition of beech leaves (F. sylvatica) was two to four times higher at forested sites compared to agricultural sites, and the most important environmental parameter that governed the variation in rates of microbial decomposition was pesticide toxicity for microorganisms ( $\left.\log \mathrm{mTU}_{\text {microbial }}\right)$ followed by pesticide toxicity for macroinvertebrates (log $\mathrm{mTU}_{\text {D.magna }}$ ) and the proportion of agriculture in the catchment. The microbial decomposition of leaf litter in agricultural streams has been investigated in several studies (Gessner and Chauvet, 1994; Hagen et al., 2006; Magbanua et al., 2010; Piscart et al., 2009). However, only two of these quantified the pesticide exposure (Schäfer et al., 2011, 2007) reporting a 2.5-4 fold reduction in leaf decomposition at agricultural sites compared to forested sites which is very comparable to our results. In contrast, the increasing eutrophication that is associated with agricultural production has been shown to increase microbial diversity, biomass and rates of decomposition (Hagen et al., 2006; Magbanua et al., 2010; Pascoal et al., 2003). Our results therefore accentuate that pesticides have an important impact on the microbial communities clearly over-ruling the well-documented and stimulating effects of eutrophication, and our results are supported

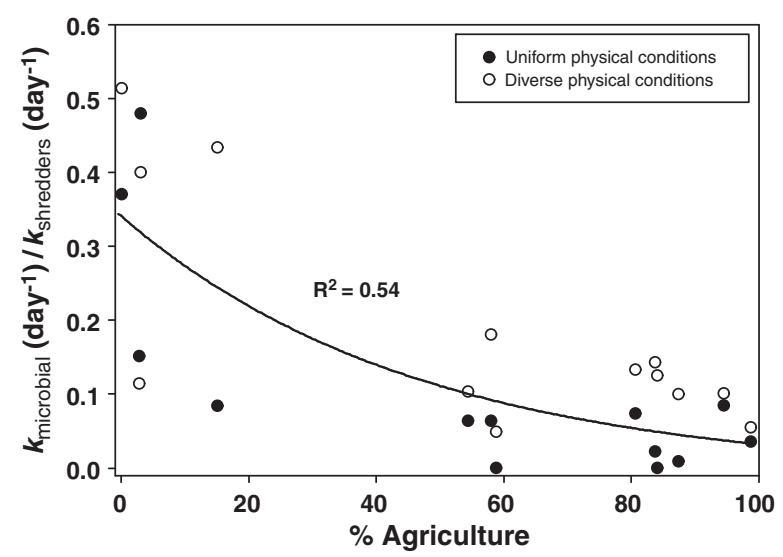

Fig. 6. The ratio between rates of microbial leaf decomposition $\left(k_{\text {microbial }}\right)$ and shredder based leaf decomposition ( $k_{\text {shredders }}$ ) as a function of the proportion of agriculture in the catchment. The data represents14 paired sites differing in the diversity of physical conditions. 
by a recent study by Schäfer et al. (2011a). Estimating pesticide toxicity to microbial decomposers is still somewhat ambiguous as none of the microbial decomposers are included as standard test organisms in the risk assessment program and thus there is only very limited toxicity data available (Dijksterhuis et al., 2011). Since the microbial decomposition is dominated by aquatic fungi (Duarte et al., 2008a, 2008b), the supplementation of toxicity data for aquatic fungi is highly important to assess the risk of pesticide impacts on this ecosystem process.

\subsection{Physical habitat properties influence the effect of pesticides on microbial leaf decomposition}

The response of microbial decomposition to increasing pesticide stress (slopes of regression lines) was similar for the two groups of sites differing in physical habitat characteristics, but the rate of microbial leaf decomposition was consistently approximately $50 \%$ lower at sites with degraded and uniform physical properties compared to sites with more undisturbed and heterogeneous physical properties. Sites with degraded and uniform physical conditions were characterised by low current velocity and high proportions of sand and silt which probably reflect higher rates of sedimentation. Rates of microbial decomposition may decrease as a direct consequence to sedimentation, because the microorganisms become curtailed in their ability to use external nutrient sources and oxygen (Barlocher, 2005; Imberger et al., 2010; Medeiros et al., 2009). The effects of reduced oxygen availability are probably further promoted by increased thickness of the boundary layer surrounding the leaf litter (Friberg et al., 2009b).

\subsection{Macroinvertebrate shredding activity}

Rates of leaf decomposition in leaf bags with macroinvertebrates were primarily correlated to the density of shredding macroinvertebrates. Surprisingly however, the density of shredding macroinvertebrates did not change significantly along the gradient of agricultural intensity in the catchment and, moreover there were no significant differences in shredder densities between sites of differing physical properties. This was mainly due to very high abundances of the freshwater amphipod, G. pulex that is generally the dominating taxon in Funen streams (Wiberg-Larsen et al., 1997). This species is very sensitive to insecticide contamination and has been shown to respond to short pulses of pyrethroids down to $10 \mathrm{ng} \mathrm{L}^{-1}$ (corresponding to $\mathrm{TU}_{\text {D.magna }}=-1.6$ ) in micro- and mesocosms (Nørum et al., 2010; Rasmussen et al., 2008). However, G. pulex also has a relatively high migration and reproduction potential (Liess and Von der Ohe, 2005), which are ecological traits that may compensate for the high sensitivity to pesticides. On the level of populations this species may therefore be rather insensitive to recurring pesticide exposure (Liess and Von der Ohe, 2005). Furthermore, G. pulex is an omnivorous species reflecting its additional ability to act as a predator and even as a grazer (Marchant, 1981; Tachet et al., 2002). The combination of diverse food preferences and ecological traits entails that G. pulex has some important competitive advantages in frequently disturbed agricultural streams making it an essential organism for the processing of organic matter in streams in Denmark. However, since pulse exposure of insecticides has been shown to change the size structure of $D$. magna through several generations (Liess and Foit, 2010; Liess et al., 2006), similar effects are likely to occur for populations of gammarids in the field. Applying shredder biomass as supplement to shredder density would have provided useful information on the size structure of the populations of gammarids in this study.

Normalising shredder decomposition to the level of individuals did not provide significant correlations with pesticide parameters suggesting that indirect effects in terms of reduced feeding rates were not detectable. These findings are contrasted by results from studies using simpler set-ups showing clear indirect effects of insecticides on Gammaridae feeding rates induced by directly exposing macroinvertebrates (Rasmussen et al., 2008) or exposing food items (Bundschuh et al., 2011). However, our study may underestimate the indirect effects of pesticides on shredding macroinvertebrates since leaf litter was not very abundant in the agricultural streams. Thus, submerged leaves could be subject to a massive feeding pressure if present gammarids preferred the submerged litter over their normal food sources.

Numerous field studies have been conducted investigating relationships between shredding activity and various sources of anthropogenic stress, but in terms of conventional agriculture the results are contrasting. A series of studies report that macroinvertebrate shredding activity was primarily explained by the density of shredders (Ferreira et al., 2006; Gessner and Chauvet, 2002; Hagen et al., 2006) whereas other studies report that rates of macroinvertebrate induced leaf decomposition congruently responded to the intensity of anthropogenic stress (Pascoal et al., 2003; Young and Collier, 2009). Piscart et al. (2009) reported that macroinvertebrate induced leaf decomposition increased with increasing density of Gammaridae and decreased with increasing agriculture in the catchment. Possibly, the density of Gammaridae decreased in response to high pesticide concentrations, but unfortunately pesticide concentrations were not measured. In contrast, Schäfer et al. (Schäfer et al., 2007) found that shredding activity was significantly correlated to the relative abundance of SPEcies At Risk (indicating direct effects of pesticides on macroinvertebrates) in French streams in which Gammaridae additionally occurred in high densities. However, the French streams represented a larger gradient of toxic pesticide pressure with measured $\mathrm{mTU}_{D \text {.magna }}$ up to -0.5 , which might have suppressed the ecological function of Gammaridae in contaminated streams (Rasmussen et al., 2008).

\subsection{Macroinvertebrate decomposers and nutritional food quality of leaves}

The relationship between rates of microbial and shredder leaf decomposition decreased with increasing proportions of agriculture in the catchment. However, the change was primarily facilitated by reduced microbial decomposition at agricultural sites as shredding activity was not significantly different amongst sites. Applying rates of microbial decomposition as a proxy for microbial biomass (Barlocher, 2005) our results indicate that the reduced palatability and nutritional value of leaves that is a consequence of reduced microbial biomass and activity had no effect on the total shredder based leaf mass loss. In existing literature it is consistently reported that shredding macroinvertebrates selectively choose highly palatable leaves with high nutritional value (Abelho, 2001; Graca, 2001). Shredding activity has been shown to decrease when either leaves (Bundschuh et al., 2011; Lauridsen et al., 2006) or macroinvertebrates (Rasmussen et al., 2008) are exposed to insecticides or fungicides. However, applied exposure concentrations in the studies of Bundschuh et al. (2011) and Lauridsen et al. (2006) were above environmental realistic concentrations and are not necessarily representative for actual field scenarios. We therefore suggest that more controlled studies using environmentally realistic exposure concentrations and durations are needed to provide the mechanistic knowledge about how microbial communities are affected and whether this change has potential to affect macroinvertebrate shredders.

\section{Conclusions}

We showed that diffuse source agricultural pesticides significantly reduced the rate of microbial leaf decomposition in agricultural streams and that pesticide toxicity for aquatic microorganisms was the primary reason for this. Based on our results we therefore propose that it is essential to consider freshwater microorganisms in risk assessment and that there is an urgent need for generating relevant toxicity data for the organisms that are at risk in the field.

An important result for the management of streams was that the quality and heterogeneity of physical habitats influence the actual effect of pesticides on microbial leaf processing emphasising the importance 
of considering the physical conditions of streams in risk assessment and mitigation.

Despite some evidence from single-organism and assemblage based micro- and mesocosm studies showing that pesticide exposure can cause indirect effects in terms of reduced feeding rates for macroinvertebrates, our results confirm that such effects are difficult to identify in complex and natural ecosystems as a result of functional redundancy and local variation in shredder abundances. However, we suggest applying other and probably more sensitive endpoints like size structure and total biomass of shredder populations to evaluate the potential effects of pesticides on shredding macroinvertebrates in the field.

Supplementary data related to this article can be found online at doi:10.1016/j.scitotenv.2011.11.057.

\section{Acknowledgements}

This study was financed by the Danish Research Council (grant no. 2104-07-0035) and is part of the RISKPOINT program. We wish to thank Johnny Nielsen for assisting in the counting and identification of macroinvertebrates. Additionally, we wish to thank Henrik Stenholt, Uffe Mensberg, Dorte Nedergaard and Marlene Venø Skjærbæk for invaluable field assistance. Søren Erik Larsen provided help with the SAS statistical software package. In addition, we thank three anonymous reviewers for very constructive comments that significantly improved the manuscript.

\section{References}

Abelho M. From litterfall to breakdown in streams: a review. Sci World 2001;1:656-80. APHA. Standard methods for the examination of water and wastewater. Washington, DC: American Public Health Association; 1998.

Barlocher F. Freshwater fungal communities. In: Deighton J, Oudemans P, White J, editors. The fungal communitiy: its organization and role in the ecosystem. Florida, United States: CRC Press; 2005. p. 39-59.

Bundschuh M, Zubrod JP, Kosol S, Maltby L, Stang C, Duester L, et al. Fungal composition on leaves explains pollutant-mediated indirect effects on amphipod feeding. Aquat Toxicol 2011:104:32-7.

Dijksterhuis J, van Doorn T, Samson R, Postma J. Effects of seven fungicides on non-target aquatic fungi. Water Air Soil Pollut 2011;222:421-5.

Duarte S, Pascoal C, Alves A, Correia A, Cassio F. Copper and zinc mixtures induce shifts in microbial communities and reduce leaf litter decomposition in streams. Freshw Biol 2008a;53:91-101.

Duarte S, Pascoal C, Cassio F. High diversity of fungi may mitigate the impact of pollution on plant litter decomposition in streams. Microb Ecol 2008b;56:688-95.

Dudgeon D, Arthington AH, Gessner MO, Kawabata ZI, Knowler DJ, Leveque C, et al. Freshwater biodiversity: importance, threats, status and conservation challenges. Biol Rev 2006;81:163-82.

Dunbar MJ, Warren M, Extence C, Baker L, Cadman D, Mould DJ, et al. Interaction between macroinvertebrates, discharge and physical habitat in upland rivers. Aquat Conserv-Mar Freshw Ecosyst 2010;20:S31-44.

Ferreira V, Gulis V, Graca MAS. Whole-stream nitrate addition affects litter decomposition and associated fungi but not invertebrates. Oecologia 2006;149:718-29.

Friberg N, Dybkjaer JB, Olafsson JS, Gislason GM, Larsen SE, Lauridsen TL. Relationships between structure and function in streams contrasting in temperature. Freshw Biol 2009a;54:2051-68.

Friberg N, Sandin L, Pedersen ML. Assessing the effects of hydromorphological degradation on macroinvertebrate indicators in rivers: examples, constraints and outlook. Integr Environ Assess Manag 2009b;5:86-96.

Friberg N, Skriver J, Larsen SE, Pedersen ML, Buffagni A. Stream macroninvertebrate occurrence along gradients in organic pollution and eutrophication. Freshw Biol 2010;55:1405-19.

Gessner MO, Chauvet E. Importance of stream microfungi in controlling breakdown rates of leaf-litter. Ecology 1994;75:1807-17.

Gessner MO, Chauvet E. A case for using litter breakdown to assess functional stream integrity. Ecol Appl 2002;12:498-510.

Gessner MO, Gulis V, Kuehn KA, Chauvet E, Suberkropp K. Fungal decomposers of plant litter in aquatic ecosystems. In: Kubicek CPaD IS, editor. Environmental and microbial relationships. 2nd edition $1 \frac{2}{2}$. Berlin: Springer Verlag; 2007.

Graca MAS. The role of invertebrates on leaf litter decomposition in streams - a review. Int Rev Hydrobiology 2001;86:383-93.

Gulis V, Ferreira V, Graca MAS. Stimulation of leaf litter decomposition and associated fungi and invertebrates by moderate eutrophication: implications for stream assessment. Freshw Biol 2006;51:1655-69.
Hagen EM, Webster JR, Benfield EF. Are leaf breakdown rates a useful measure of stream integrity along an agricultural landuse gradient? J North Am Benthological Soc 2006;25:330-43.

Imberger SJ, Thompson RM, Grace MR. Searching for effective indicators of ecosystem function in urban streams: assessing cellulose decomposition potential. Freshw Biol 2010:55:2089-106.

Kjeldahl J. A new method for the determination of nitrogen in organic matter. Zeitschreft fur Analytische Chemie 1883;22:366.

Kronvang B, Strom HL, Hoffmann CC, Laubel A, Friberg N. Subsurface tile drainage loss of modern pesticides: field experiment results. Water Sci Technol 2002;49:139-47.

Lauridsen RB, Kronvang B, Friberg N. Occurrence of sediment-bound pyrethroids in danish streams and their impact on ecosystem function. Water Air Soil Pollut 2006;6:423-32.

Liess M, Foit K. Intraspecific competition delays recovery of population structure. Aquat Toxicol 2010;97:15-22.

Liess M, Von der Ohe PC. Analyzing effects of pesticides on invertebrate communities in streams. Environ Toxicol Chem 2005;24:954-65.

Liess M, Brown CD, Dohmen GP, Duquesne S, Hart A, Heimbach F, et al. Effects of pesticides in the field. Berlin, Germany: SETAC press; 2005.

Liess M, Pieters BJ, Duquesne S. Long-term signal of population disturbance after pulse exposure to an insecticide: rapid recovery of abundance, persistent alteration of structure. Environ Toxicol Chem 2006;25:1326-31.

Magbanua FS, Townsend CR, Blackwell GL, Phillips N, Matthaei CD. Responses of stream macroinvertebrates and ecosystem function to conventional, integrated and organic farming. J Appl Ecol 2010;47:1014-25.

Maltby L, Brock TCM, van den Brink PJ. Fungicide risk assessment for aquatic ecosystems: importance of interspecific variation, toxic mode of action, and exposure regime. Environ Sci Technol 2009;43:7556-63.

Marchant R. The ecology of Gammarus in running water. In: Lock MA, Williams DD, editors. Perspectives in running water ecology. New York, USA: Plenum Press; 1981. p. 225-50.

Medeiros AO, Pascoal C, Graca MAS. Diversity and activity of aquatic fungi under low oxygen conditions. Freshw Biol 2009;54:142-9.

Meybeck M. Global analysis of river systems: from Earth system controls to Anthropocene syndromes. Philos Trans R Soc B 2003;358:1935-55.

Millenium Ecosystem Assessment. Ecosystems and human well-being: synthesis. Washington, DC: Island Press, 2005.

Neumann M, Schutz R, Schafer K, Muller W, Mannheller W, Liess M. The significance of entry routes as point and non-point sources of pesticides in small streams. Water Res 2002;36:835-42.

Nørum U, Friberg N, Jensen M, Pedersen J, Bjerregaard P. Behavioural changes in three species of freshwater macroinvertebrates exposed to the pyrethroid lambda-cyhalothrin: laboratory and stream microcosm studies. Aquat Toxicol 2010;98:328-35.

Pascoal C, Pinho M, Cassio F, Gomes P. Assessing structural and functional ecosystem condition using leaf breakdown: studies on a polluted river. Freshw Biol 2003;48:2033-44.

Pedersen ML. Effects of channelisation, riparian structure and catchment area on physical habitats in small lowland streams. Fundam Appl Limnol 2009;174:89-99.

Pedersen ML, Friberg N. Influence of disturbance on habitats and biological communities in lowland streams. Fundam Appl Limnol 2009;174:27-41.

Piscart C, Genoel R, Doledec S, Chauvet E, Marmonier P. Effects of intense agricultural practices on heterotrophic processes in streams. Environ Pollut 2009;157:1011-8.

Rasmussen JJ, Friberg N, Larsen SE. Impact of lambda-cyhalothrin on a macroinvertebrate assemblage in outdoor experimental channels: implications for ecosystem functioning. Aquat Toxicol 2008;90:228-34.

Rasmussen JJ, Baattrup-Pedersen A, Larsen SE, Kronvang B. Local physical habitat quality cloud the effect of predicted pesticide runoff from agricultural land in Danish streams. J Environ Monit 2011a;13:943-50.

Rasmussen J, Baattrup-Pedersen A, Wiberg-Larsen P, Kronvang B. Buffer strip width and agricultural pesticide contamination in Danish lowland streams: implication for stream and riparian management. Ecol Eng 2011b;37:1990-7.

Schäfer RB, Caquet T, Siimes K, Mueller R, Lagadic L, Liess M. Effects of pesticides on community structure and ecosystem functions in agricultural streams of three biogeographical regions in Europe. Sci Total Environ 2007;382:272-85.

Schäfer RB, Pettigrove V, Rose G, Allinson G, Wightwick A, von der Ohe PC, et al. Effects of pesticides monitored with three sampling methods in 24 sites on macroinvertebrates and microorganisms. Environ Sci Technol 2011;45:1665-72.

Schäfer RB, Bundschuh M, Rouch DA, E.S., Von der Ohe PC, Pettigrove V, et al. Effects of pesticide toxicity, salinity and other environmental variables on selected ecosystem functions in streams and the relevance for ecosystem services. Sci Total Environ in press, doi:10.1016/j.scitotenv.2011.05.063.

Schulz R. Field studies on exposure, effects, and risk mitigation of aquatic nonpoint-source insecticide pollution: a review. J Environ Qual 2004;33:419-48.

Tachet H, Richoux P, Bournard M, Usseglio-Polatera P. Invertébrés D'eau Douce: Systematique, biologie, écologie. Paris: CRNS Editions; 2002.

Wauchope RD. Pesticide content of surface-water draining from agricultural fields - review. Environ Qual 1978;7:459-72.

Wiberg-Larsen P, Pedersen SE, Tornbjerg NH, Sode A, Muus K, Wehrs M. The Funen streams. Aquatic environmental monitoring: theme: freshwater. Funen CountyOdense: Dept. of Nature and Aquatic Environment; 1997. p. 209.

Young RG, Collier KJ. Contrasting responses to catchment modification among a range of functional and structural indicators of river ecosystem health. Freshw Biol 2009;54:2155-70.

Young RG, Matthaei CD, Townsend CR. Organic matter breakdown and ecosystem metabolism: functional indicators for assessing river ecosystem health. J North Am Benthological Soc 2008;27:605-25. 